\title{
Effects of common metal ions on the determination of anions by suppressed ion chromatography
}

\author{
Yongsheng Ding, Shifen Mou* \\ Research Center for Eco-Environmental Sciences, Chinese Academy of Science, P.O. Box 2871, Beijing 100085, PR China
}

\begin{abstract}
The effects of common metal ions $\left(\mathrm{Na}^{+}, \mathrm{K}^{+}, \mathrm{Ca}^{2+}, \mathrm{Mg}^{2+}, \mathrm{Al}^{3+}\right.$ and $\left.\mathrm{Fe}^{3+}\right)$ on the determination of nitrate, phosphate and sulfate by suppressed ion chromatography were investigated. The responses of nitrate within $1-10 \mathrm{mg} / 1$ were not affected in the presence of six metal ions at $10 \mathrm{mg} / 1$. The peak areas of $1.0 \mathrm{mg} / 1$ sulfate increased significantly at $10 \mathrm{mg} / 1 \mathrm{Fe}^{3+}$ or $\mathrm{Al}^{3+}$ up to 51.34 and $48.37 \%$, respectively. In the presence of $10 \mathrm{mg} / 1 \mathrm{Fe}^{3+}$, the peak area of $1 \mathrm{mg} / 1 \mathrm{and} 10 \mathrm{mg} / 1 \mathrm{phosphates}$ decreased by 91.44 and $33.71 \%$, respectively. At $10 \mathrm{mg} / 1 \mathrm{Al}^{3+}$ the peak areas of phosphate also increased slightly. The adverse effect of $\mathrm{Fe}^{3+}$ on the determination of phosphate could be overcome effectively by reducing the $\mathrm{pH}$ of the samples. The method to overcome the adverse effect was studied. (c) 2002 Elsevier Science B.V. All rights reserved.
\end{abstract}

Keywords: Metal cations; Inorganic anions

\section{Introduction}

Since its introduction in 1975 by Small et al. [1], ion chromatography (IC) has emerged as a powerful tool for the analysis of trace ions, especially for anions. Although suppressed IC has become well established for the determination of common anions in many fields, the determination of a small concentration of anions in the presence of a large concentration of other ions often produces inaccurate results.

Bynum et al. [2] reported that the determination of $0-100 \mathrm{mg} / 1$ sulfate was influenced by the presence of $8000 \mathrm{mg} / \mathrm{l}$ or higher of chloride. Smith [3]

\footnotetext{
*Corresponding author. Tel.: + 86-10-62849-239; fax: + 86-1062849-239.

E-mail address: shifenm@mail.rcees.ac.cn (S. Mou).
}

described the effect of a large amount of hydroxide or sulfate on the behavior of chloride. The chloride peak heights and retention times were found to depend upon their concentrations. Singh et al. [4] addressed that the determination of sulfate in the sample with a very high concentration of metal chlorides was affected by the large amount of metal ions in the medium. They presumed that when the cation concentration in the influent suddenly increased due to the presence of large amounts of cations such as $\mathrm{Na}^{+}, \mathrm{Ca}^{2+}$, or $\mathrm{Mg}^{2+}$ during the ion-exchange process, a significant accumulation of $\mathrm{H}^{+}$ions on the surface of the suppressor might have occurred. The accumulation of $\mathrm{H}^{+}$ions at the surface of the suppressor can cause the formation of the $\mathrm{HSO}_{4}^{-}$ion pair after reacting with $\mathrm{SO}_{4}^{2-}$. The formation of the $\mathrm{HSO}_{4}^{-}$ion pair causes a decrease in the conductivity of sulfate ions due to the reduction in total ionic charge. 
Owing to various interferences in real samples, the analysis of phosphate has not been satisfactory for a long time [5]. Many methods have been used to eliminate these adverse effects of high levels of interfering anions on the determination of phosphate and improve the recovery of phosphate. First, the concentration of the matrix ions in the sample could be reduced prior to the analysis by using a suitable pre-column filled with an ion-exchange resin (in the form of $\mathrm{Ag}^{+}$or $\mathrm{Ba}^{2+}$ ) [6-8], hollow-fibre ionexchange membranes [9] or dialysis through membranes [10]. Other approaches to eliminate matrix contaminants used on-line heart-cutting or recycling methods [11,12]. However, all these methods generally had low recoveries of phosphate and were time consuming.

To our knowledge, little information is available about the influence of metal ions on the analysis of anions by IC, especially phosphate. In this paper, the influences of metal ions on phosphate, sulfate and nitrate were described and the elimination of the adverse effect of $\mathrm{Fe}^{3+}$ on the analysis of phosphate was investigated. These results may be beneficial to the users of suppressed ion chromatography involved in similar analysis.

\section{Experimental}

\subsection{Instrumentation}

The ion chromatograph used for this work was a Dionex (Sunnyvale, CA, USA) DX-300 IC system consisting of a gradient pump and conductivity detector. Separations were carried out using a Dionex IonPac AS14 analytical column with an IonPac AG14 guard column. The experimental conditions were as follows: sample loop, $50 \mu l$; eluent, $3.5 \mathrm{~m} M$ sodium carbonate- $1.0 \mathrm{~m} M$ sodium hydrogencarbonate; flow-rate, $1.2 \mathrm{ml} / \mathrm{min}$. Anions were detected by suppressed conductivity detection. Suppression was achieved by using a Dionex ASRSULTRA. A Dionex PeakNet chromatography workstation was utilized to control the instrument and for data processing.

\subsection{Reagents and procedures}

All reagents used were of analytical reagent grade or better (obtained from different suppliers). Three analyte anions were prepared from $\mathrm{NaNO}_{3}, \mathrm{KH}_{2} \mathrm{PO}_{4}$ and $\mathrm{Na}_{2} \mathrm{SO}_{4}$, respectively. All the metal ions were prepared from their chlorides. A $1000 \mathrm{mg} / \mathrm{l}$ stock solution of each ion was prepared in $18 \mathrm{M} \Omega$ water and used for further dilutions. All of the sample solutions were filtered through a membrane filter $(0.45 \mu \mathrm{m})$ prior to injection. Stock solutions were stored at $4{ }^{\circ} \mathrm{C}$.

\section{Results and discussion}

\subsection{The basic data of anions}

Three anions $\left(\mathrm{NO}_{3}^{-}, \mathrm{PO}_{4}^{3-}\right.$ and $\left.\mathrm{SO}_{4}^{2-}\right)$ and six common metal ions $\left(\mathrm{Na}^{+}, \mathrm{K}^{+}, \mathrm{Ca}^{2+}, \mathrm{Mg}^{2+}, \mathrm{Al}^{3+}\right.$ and $\mathrm{Fe}^{3+}$ ) were selected for this study because: (i) three anion peaks could be well separated; and (ii) they were of interest and commonly found in environmental analysis. In order to avoid the effect of high levels of chloride on analyzed anions and the overload to the AS14 column (a medium capacity column), the concentrations of metal ions used were $10 \mathrm{mg} / 1$ in this experiment. Generally, the concentrations of $1-10 \mathrm{mg} / 1$ were calibrated for quantitative analysis of anions, so the concentration of 1 $\mathrm{mg} / \mathrm{l}$ and $10 \mathrm{mg} / \mathrm{l}$ were selected for anion analysis in this test. The relative standard deviations (RSDs) of the peak areas were less than $2.7 \%$ (data from seven consecutive injections).

\subsection{Effects of metal ions on the response of anions}

The effect of six metal ions $\left(\mathrm{Na}^{+}, \mathrm{K}^{+}, \mathrm{Ca}^{2+}\right.$, $\mathrm{Mg}^{2+}, \mathrm{Al}^{3+}$ and $\mathrm{Fe}^{3+}$ ) on the peak area response of nitrate, phosphate and sulfate were summarized in Table 1 . The peak areas of $1-10 \mathrm{mg} / 1$ nitrate were relatively stable in the presence of $10 \mathrm{mg} / 1 \mathrm{metal}$ ions, respectively. This indicates that the peak areas of $1-10 \mathrm{mg} / \mathrm{l}$ nitrate were slightly affected by the presence of $10 \mathrm{mg} / \mathrm{l}$ of metal ions.

Although peak areas of sulfate were relatively stable in the presence of $\mathrm{Na}^{+}, \mathrm{K}^{+}, \mathrm{Ca}^{2+}$ or $\mathrm{Mg}^{2+}$, the peak areas of $1.0 \mathrm{mg} / 1$ sulfate at $10 \mathrm{mg} / 1 \mathrm{Al}^{3+}$ or $\mathrm{Fe}^{3+}$ were affected with variations of +48.37 and $+51.34 \%$, respectively. This result could be ex- 
Table 1

Effects of $10 \mathrm{mg} / \mathrm{l}$ metal ions on the response of anions

\begin{tabular}{|c|c|c|c|c|c|c|}
\hline \multirow[t]{2}{*}{ Metal ions } & \multicolumn{2}{|c|}{ Nitrate, $\%$ variation } & \multicolumn{2}{|c|}{ Phosphate, \% variation } & \multicolumn{2}{|c|}{ Sulfate, $\%$ variation } \\
\hline & $1.0 \mathrm{mg} / 1$ & $10.0 \mathrm{mg} / 1$ & $1.0 \mathrm{mg} / 1$ & $10.0 \mathrm{mg} / 1$ & $1.0 \mathrm{mg} / 1$ & $10.0 \mathrm{mg} / 1$ \\
\hline $\mathrm{Na}^{+}$ & +1.23 & -1.28 & +4.58 & -2.22 & +2.06 & -2.49 \\
\hline $\mathrm{K}^{+}$ & -0.26 & +1.37 & -0.82 & +1.22 & +2.69 & +0.71 \\
\hline $\mathrm{Ca}^{2+}$ & -0.83 & -1.86 & +7.99 & +4.24 & +2.56 & +2.09 \\
\hline $\mathrm{Mg}^{2+}$ & +0.87 & -1.80 & +9.36 & +3.49 & +4.81 & +3.00 \\
\hline $\mathrm{Al}^{3+}$ & -1.62 & -1.03 & +15.97 & +4.41 & +48.37 & +6.76 \\
\hline $\mathrm{Fe}^{3+}$ & -1.06 & -0.75 & -91.44 & -33.71 & +51.34 & +20.27 \\
\hline
\end{tabular}

Percentage variations come from the peak area of anions in the presence of metal ions in samples against the peak areas of anions in the absence of the metal ions, all of the peak areas are averages of triplicate injections.

plained as follows: In a typical anion-exchange resin (e.g. IonPac AS14), beads of surface sulfonated styrene-divinyl benzene were contacted with a suspension of colloidal anion-exchange material. The cationic functionality of the small particles was attracted to the anionic sulfate groups on the larger bead by a strong electrostatic attachment [13]. The anionic sulfate groups on the large bead could not be covered completely by the cationic functionality of the small particles in the column. When the column was washed with the eluent containing a large amount of $\mathrm{Na}^{+}$, the uncovered sulfate groups were combined with sodium by electrostatic interaction. The polyvalent metal ions in the sample (such as $\mathrm{Ca}^{2+}, \mathrm{Mg}^{2+}, \mathrm{Al}^{3+}$ and $\mathrm{Fe}^{3+}$ ) were prone to be attracted to the uncovered sulfate groups in place of $\mathrm{Na}^{+}$. The reaction is reversible so that sufficient $\mathrm{Na}^{+}$ in the eluent could displace the polyvalent metal ions downwards in the column as they undergo further exchanges between the solution and resin phases. Finally, the polyvalent metal ions eluted with some analyte anions. This process may be represented simply as:

$$
\begin{aligned}
& \mathrm{R}-\mathrm{SO}_{3}^{-} \mathrm{H}^{+}+\mathrm{Na}^{+} \rightarrow \mathrm{R}-\mathrm{SO}_{3}^{-} \mathrm{Na}^{+}+\mathrm{H}^{+} \\
& \mathrm{R}-\mathrm{SO}_{3}^{-} \mathrm{Na}^{+}+\mathrm{M}^{n+} \rightarrow \mathrm{R}-\mathrm{SO}_{3}^{-} \mathrm{M}^{n+}+\mathrm{Na}^{+} \\
& \mathrm{R}-\mathrm{SO}_{3}^{-} \mathrm{M}^{n+}+\mathrm{Na}^{+} \rightarrow \mathrm{R}-\mathrm{SO}_{3}^{-} \mathrm{Na}^{+}+\mathrm{M}^{n+}
\end{aligned}
$$

On the basis of the number of the metal ion charge, the trivalent metal ions were held more strongly than divalent and univalent metal ions, then accompanied by anions such as sulfate and phos- phate, were eluted out. In suppressed IC, the suppressor exchanged all the influent cations for $\mathrm{H}^{+}$and reduced the eluent (a mixture of sodium hydrogencarbonate and sodium carbonate, for anion analysis) background to that of weakly conducting $\mathrm{H}_{2} \mathrm{CO}_{3}$. At the same time, the suppressor converted the common anions $\mathrm{Cl}^{-}, \mathrm{Br}^{-}, \mathrm{I}^{-}$and $\mathrm{SO}_{4}^{2-}$ to strongly ionized acids $\mathrm{HCl}, \mathrm{HBr}, \mathrm{HI}$ and $\mathrm{H}_{2} \mathrm{SO}_{4}$, which were detectable with excellent sensitivity [1]. When $\mathrm{Al}^{3+}$ or $\mathrm{Fe}^{3+}$ was eluted with anions in the suppressor, the cations would exchange protons with the rate of $1: 3$ so that the concentration of protons in the suppressor was higher than that of protons in the presence of $\mathrm{Na}^{+}$by exchanging protons with the rate of 1:1. A high concentration of proton in the suppressor could improve the formation of carbonic acid so that the eluent background was reduced more than before. Fig. 1. shows the chromatograms of 1 $\mathrm{mg} / \mathrm{l}$ (A) and $10 \mathrm{mg} / \mathrm{l}$ (B) anions in the presence of $10 \mathrm{mg} / 1 \mathrm{Al}^{3+}$ and $\mathrm{Fe}^{3+}$. In Fig. 1, the retention times of anions were shorter in the presence of $\mathrm{Al}^{3+}$ or $\mathrm{Fe}^{3+}$ than when $\mathrm{Al}^{3+}$ or $\mathrm{Fe}^{3+}$ were absent. The shorter retention times might be due to the hydroxides from the hydrolysis of the trivalent ions. The compounds of hydroxide could bring the efficiency of the column down. However, it is necessary to state that this result is contrary to the result that Singh et al. have found. In their experiment, the salt concentrations were very high, up to several hundred milligrams per litre, but in our experiment, the concentration of metal ions in the sample solution was only $10 \mathrm{mg} / \mathrm{l}$. In addition, they only discussed the effects of sodium chloride on sulfate and the effects of $\mathrm{Ca}^{2+}$ and $\mathrm{Mn}^{2+}$ on oxalate. The trivalent metal ions were not mentioned. 

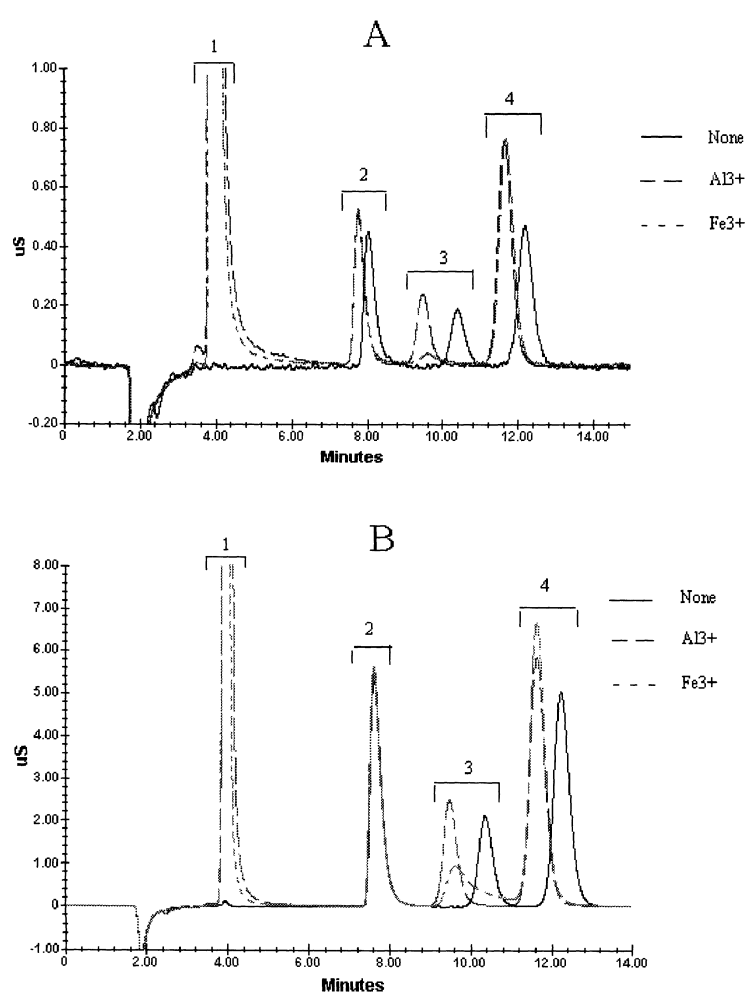

Fig. 1. Chromatograms of $1 \mathrm{mg} / 1$ (A) and $10 \mathrm{mg} / 1$ (B) anions in the presence of $10 \mathrm{mg} / 1 \mathrm{Al}^{3+}$ and $\mathrm{Fe}^{3+}$. (1) Chloride, (2) nitrate, (3) phosphate, (4) sulfate.

It was obvious from the results in Table 1 that phosphate analysis was unreliable in the presence of $\mathrm{Fe}^{3+}, \mathrm{Al}^{3+}, \mathrm{Mg}^{2+}$ and $\mathrm{Ca}^{2+}$. The effect of $\mathrm{Fe}^{3+}$ on the response of phosphate was most serious in six metal ions. In the presence of $10 \mathrm{mg} / 1 \mathrm{Fe}^{3+}$, the peak areas of 1 and $10 \mathrm{mg} / 1$ of phosphate decreased by 91.44 and $33.71 \%$, respectively, against that in the absence of $\mathrm{Fe}^{3+}$. This was mainly due to the fact that phosphate was a complexing agent and could form complexes with $\mathrm{Fe}^{3+}$ in basic solution. The stability constant $(\log \beta)$ of $\mathrm{Fe}^{3+}-\mathrm{HPO}_{4}^{2-}$ was very high (9.75). Although $\mathrm{Ca}^{2+}$ and $\mathrm{Mg}^{2+}$ also could form complexes with phosphate in basic solution, the complexing was much lower than that of $\mathrm{Fe}^{3+}$. In the presence of $10 \mathrm{mg} / 1 \mathrm{Ca}^{2+}, \mathrm{Mg}^{2+}$ or $\mathrm{Al}^{3+}$, the responses of $1 \mathrm{mg} / 1$ phosphate increased greater than that of $10 \mathrm{mg} / \mathrm{l}$ phosphate, respectively. The retention time of phosphate in the presence of $\mathrm{Al}^{3+}$ and $\mathrm{Fe}^{3+}$ also decreased greatly. The effects of $\mathrm{Al}^{3+}$ on phosphate were similar to the effects of trivalent metal ions on sulfate described above.

\subsection{Effect of $\mathrm{pH}$ on the peak areas of phosphate in the presence of $\mathrm{Fe}^{3+}$}

Complexation between $\mathrm{Fe}^{3+}$ and phosphate resulted in a decreased response of phosphate and the peak shape of phosphate tailed severely. Phosphate acid had three grades of dissociation equilibrium with the dissociation constants $\mathrm{p} K_{1}(2.17), \mathrm{p} K_{2}(7.65)$ and $\mathrm{p} K_{3}(10.20)$. The concentration of $\mathrm{HPO}_{4}^{2-}$ could

Table 2

Effects of $\mathrm{pH}$ on the peak area of $1 \mathrm{mg} / 1$ phosphate in the presence of $10 \mathrm{mg} / 1 \mathrm{Fe}^{3+}$

\begin{tabular}{lll}
\hline $\mathrm{pH}$ & Peak area & Reduction $(\%)$ \\
\hline 5.4 & 5520 & ${\left.\text { (without } \mathrm{Fe}^{3+}\right)}^{3+}$ \\
3.8 & 476 & -91.36 \\
2.5 & 4172 & -24.41 \\
2.0 & 4968 & -10.00 \\
1.5 & 4352 & -21.16 \\
1.0 & 3983 & -27.84 \\
\hline
\end{tabular}

Percentage reduction, as compared to the peak area of pure phosphate, all of the peak areas are averages of triplicate injections.

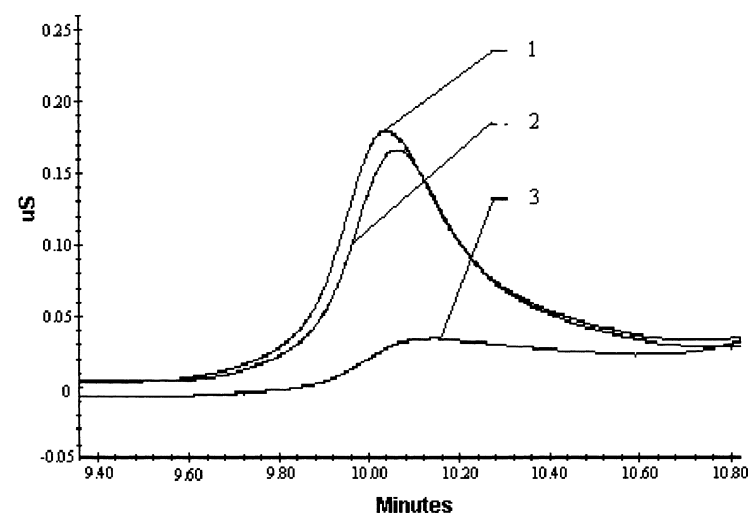

Fig. 2. Effect of the $\mathrm{pH}$ on $1.0 \mathrm{mg} / 1$ phosphate in the presence of $10 \mathrm{mg} / 1 \mathrm{Fe}^{3+}$. (1) $1 \mathrm{mg} / 1$ phosphate standard $\mathrm{pH} 2.0$; (2) $1 \mathrm{mg} / 1$ phosphate $+10 \mathrm{mg} / 1 \mathrm{Fe}^{3+}, \mathrm{pH} 2.0$; (3) $1 \mathrm{mg} / 1$ phosphate +10 $\mathrm{mg} / 1 \mathrm{Fe}^{3+}, \mathrm{pH} 3.8$. 
Table 3

The recoveries of anions in the samples $(n=5)$

\begin{tabular}{|c|c|c|c|c|}
\hline \multirow[t]{2}{*}{ Sample } & \multirow[t]{2}{*}{$\mathrm{pH}$} & \multicolumn{3}{|c|}{ Recovery (\%) } \\
\hline & & Nitrate & Phosphate & Sulfate \\
\hline \multirow[t]{2}{*}{ Anions: $\mathrm{Fe}^{3+}(1: 10 \mathrm{mg} / \mathrm{l})$} & 3.8 & 101.2 & 11.42 & 153.6 \\
\hline & 2.0 & 99.67 & 97.25 & 103.4 \\
\hline \multirow[t]{2}{*}{ Anions: $\mathrm{Fe}^{3+}(10: 10 \mathrm{mg} / 1)$} & 3.8 & 100.3 & 75.32 & 105.6 \\
\hline & 2.0 & 100.5 & 98.45 & 102.4 \\
\hline \multirow[t]{2}{*}{ Tap water 1} & 6.9 & 100.2 & 43.60 & 110.0 \\
\hline & 2.0 & 101.1 & 82.47 & 97.55 \\
\hline \multirow[t]{2}{*}{ Tap water 2} & 7.0 & 99.80 & 52.36 & 109.8 \\
\hline & 2.0 & 100.1 & 89.64 & 102.9 \\
\hline
\end{tabular}

be changed within the different pH's of the solutions. In the low $\mathrm{pH}$ range, the complexation between $\mathrm{Fe}^{3+}$ and $\mathrm{HPO}_{4}^{2-}$ will be restrained. Table 2 showed the effects of the $\mathrm{pH}$ on the response of phosphate in samples containing $1 \mathrm{mg} / 1$ phosphate and $10 \mathrm{mg} / 1$ $\mathrm{Fe}^{3+}$. The peak areas of phosphate in the presence of $\mathrm{Fe}^{3+}$ arrived at maximum values when the $\mathrm{pH}$ of samples was near to 2.0. At the same time, the peak shape of phosphate was improved (see Fig. 2). The peak area of $1.0 \mathrm{mg} / 1$ phosphate at $10 \mathrm{mg} / 1 \mathrm{Fe}^{3+}$ was about $90 \%$ of the peak area of pure phosphate. This indicated that reducing the $\mathrm{pH}$ value of the sample solution could help to settle the problem during the determination of phosphate in the presence of large concentrations of $\mathrm{Fe}^{3+}$.

When the $\mathrm{pH}$ of the sample was lower than 2.0, not only the sensitivity of phosphate reduced for the increase of $\mathrm{H}_{3} \mathrm{PO}_{4}$, but also the acid added could change the ratio of $\mathrm{HCO}_{3}^{-} / \mathrm{CO}_{3}^{2-}$. It was necessary to run a calibration standard under the same $\mathrm{pH}$ of solution for analysis of phosphate.

\subsection{Recovery test}

Under the chosen conditions, the recovery tests were shown in Table 3. It was found that good results could be achieved in the low $\mathrm{pH}$ range of samples. Although the obtained recoveries of phosphate in tap water with acid added was not sufficiently high, the results were better than without acid added. Reducing the $\mathrm{pH}$ of the sample solution could help to determine the phosphate as accurately as possible.

\section{Conclusion}

On the basis of the results presented in this paper, we could conclude that: the peak areas and retention times of $1-10 \mathrm{mg} / 1$ nitrate were slightly affected in the presence of $10 \mathrm{mg} / 1$ of six metal ions $\left(\mathrm{Na}^{+}, \mathrm{K}^{+}\right.$, $\mathrm{Ca}^{2+}, \mathrm{Mg}^{2+}, \mathrm{Al}^{3+}$ and $\left.\mathrm{Fe}^{3+}\right)$, respectively. However, the accurate analysis of phosphate and sulfate in the presence of $\mathrm{Fe}^{3+}$ and $\mathrm{Al}^{3+}$ by suppressed IC needed caution. In the case of $10 \mathrm{mg} / 1 \mathrm{Al}^{3+}$, the responses of sulfate and phosphate at $1-10 \mathrm{mg} / \mathrm{l}$ enlarged and the retention times were shortened. The effects of $10 \mathrm{mg} / 1 \mathrm{Fe}^{3+}$ on 1-10 $\mathrm{mg} / 1$ phosphate and sulfate were most serious in the six metal ions. Not only did the peak area of phosphate decrease and the peak area of sulfate increase, but also the retention times of the two anions were greatly shortened. Generally, the effects of the trivalent metal ions on the analysis of anions were more serious than the effects of divalent and univalent metal ions. Moreover, the influences of $10 \mathrm{mg} / \mathrm{l}$ metal ions on anions at $1 \mathrm{mg} / 1$ were larger than on the anions at $10 \mathrm{mg} / \mathrm{l}$. When the amount of metal ions (i.e. polyvalent metal ions) in the samples was higher than that of analyte anions (i.e. phosphate and sulfate), the adverse effects needed to be dealt with in the analysis of anions. Hydrochloric acid was used to adjust the $\mathrm{pH}$ of the sample solution to 2.0 in order to overcome the adverse effect of $\mathrm{Fe}^{3+}$ on the determination of phosphate. The precipitation of $\mathrm{Al}^{3+}$ and $\mathrm{Fe}^{3+}$ in the basic solution also could be used to remove a large amount of such metal ions in the sample. Briefly, the effects of the metal ions on 
the response of anions should not be ignored in daily experiments.

\section{References}

[1] H. Small, T.S. Stevens, W.C. Bauman, Anal. Chem. 47 (1975) 1801.

[2] M.A.O. Bynum, S.Y. Tyree Jr., W.E. Weiser, Anal. Chem. 53 (1981) 1935.

[3] R.E. Smith, Anal. Chem. 55 (1983) 1429.

[4] R.P. Singh, E.R. Pambid, N.M. Abbas, Anal. Chem. 63 (1991) 1897.
[5] D. Kirkwood, A. Aminot, M. Perttila, International Council for the Exploration of the Sea Cooperative Research Report, Copenhagen, 1991, p. 174.

[6] P.R. Haddad, J. Chromatogr. 482 (1989) 267.

[7] S.Y. Tyree Jr., M.A.O. Bynum, Limnol. Oceanogr. 29 (1984) 1337.

[8] M.T. Galceran, M. Diez, J. Chromatogr. A 657 (1993) 77.

[9] P.E. Jackson, W.R. Jones, J. Chromatogr. 538 (1991) 497.

[10] J.A. Cox, N. Tanaka, Anal. Chem. 57 (1985) 383.

[11] M. Murayama, M. Suzuki, S. Takitani, J. Chromatogr. 466 (1989) 355.

[12] S.R. Villasenor, Anal. Chem. 63 (1991) 1362.

[13] H. Small, Ion Chromatography, Plenum Press, New York, 1989, p. 46. 